\title{
Research on the Application and the Development of the Glass Concrete in Civil Engineering
}

\author{
Shilong Jia ${ }^{1, a}$, Kaihui Chen ${ }^{1, b}$ and Zhongliang Chen ${ }^{2, c}$ \\ ${ }^{1}$ School of Civil Engineering, Shenyang Jianzhu University, Shenyang, 110168, China \\ 2 Shenyang Wan yin New Town Construction Investment Co., Ltd., Shenyang, 110000, China \\ a email: 3093866754@qq.com, bemail: 516298111@qq.com, ${ }^{c}$ email: 2846491929@qq.com,
}

\section{Keywords: Waste Glass; Concrete; Civil Engineering; Feasibility}

Abstract. The glass concrete saves a lot of sandstone resources and it solves the problem of waste glass reuse at the mean while. There are many researches on the application of glass concrete in civil engineering field at home and abroad. The theoretical achievements are remarkable, but the practical application is few. Only the glass asphalt concrete is widely used in foreign countries. At present, our country is still in the preliminary stage of theoretical research. The research achievements and problems exist side by side, and there is still a gap between research achievements and the actual application. However, the research has fully shown that the function of glass concrete with appropriate particle size is similar to that of ordinary concrete, and some of the functions are better than the functions of ordinary concrete. It is feasible that the glass asphalt concrete is used in the construction project.

\section{The Background and the Significance of the Research}

The concrete is the main building material, and is widely used in the civil engineering project. The ordinary concrete is mainly composed of cement, sand, stone and water. The Sand and the stone serve as the coarse aggregate and the fine aggregate in the concrete and are the main ingredients of the concrete. According to the relevant statistics, we consume 10 billion tons of the sand and the stone in the process of batching the concrete in china every year ${ }^{[1]}$. The excessive exploitation of the sand and the stone causes the adverse effects on the environment. On the one hand, because the sand and the stone are nonrenewable natural resources, excessive mining will cause the shortage of raw materials in the future. The development of new ingredients will solve the problems caused by the long-distance transition of resources, such as the increase of the freight and the rising cost of the concrete. On the other hand, the mechanized mining causes the noise pollution, the light pollution, the dust pollution and other kinds of pollutions, and also makes the river polluted and the course of river diverted, and has mountain vegetation destroyed and causes the landslide in adverse weather condition and other kinds of geological disasters.

With the development of science and economy in China, the demand for glass products is growing increasingly in life and production. At the same time, there are about 450 750 million tons of waste glass produced every year ${ }^{[2]}$. The recycling and reuse rate is less than $20 \%$ because the research on the reuse of waste glass starts late in China. Large amount of waste glass is treated by the traditional landfill disposal, and this kind of glass waste treatment causes the waste of resources and also damages the soil environment seriously because glass is non-biodegradable material.

Crush the waste glass into particles with appropriate size, and make the glass particles into glass concrete by mixing a certain amount of glass particles into the concrete instead of the sand and the stone. Through the study of various parameters and properties of glass concrete, it is actually applied in the field of civil engineering. The application can not only create a new method of recycling waste, but also save a large amount of sandstone and other natural resources. The application is in accordance with the national strategy of sustainable development and is of great significance in energy conservation and environmental protection. 


\section{The Situation of the Relevant Research at Home and Abroad}

The research of recycling and reuse of waste glass is started earlier in developed countries and regions, and the utilization rate of the waste glass in many countries is over $70 \%{ }^{[3]}$ in Europe. The researches on the application of waste glass in concrete have obtained fruitful achievements in practice in The United States, Canada, South Korea, Hong Kong, Taiwan and other countries and regions. Some of the countries have made glass asphalt concrete, and glass asphalt concrete is widely used in engineering project. Research on glass concrete is developed late in our country, and is still in theoretical research stage. The main results are related to the size and content of glass aggregate, mechanics and durability, alkali-silicate reaction, glass concrete beam and so on.

Research on the Influence of Glass Particle Size and Content on Glass Concrete Properties. In order to find out the influence of the glass' size on the strength of glass concrete(The six kinds of diameters of the particle are $2.36-1.18 \mathrm{~mm}, 1.18-0.60 \mathrm{~mm}, 0.60-0.30 \mathrm{~mm}, 0.30-0.15 \mathrm{~mm}$, $0.15-0.075 \mathrm{~mm}$, and $<0.075 \mathrm{~mm})$, the researchers make 6 glass concrete specimens of 450 grams of cement and 1350 grams with broken glass. The amount of water taken is $225 \mathrm{ml}, 225 \mathrm{ml}, 250 \mathrm{ml}$, $335 \mathrm{ml}, 500 \mathrm{ml}$, and $550 \mathrm{ml}$ respectively. The compressive strength and the flexural strength of each specimen are measured in different ages of the concrete, namely 3 days, 7 days, 14 days, 28 days and 60 days. By comparing the strength of six specimens at different ages, the researchers conclude that the strength of glass concrete lost with the growth of the age of the concrete when the diameter of the glass particle greater than $1.18 \mathrm{~mm}$, and this kind of glass particles would have the alkali-silica reaction. It is necessary to add Alkali-silicon reaction inhibitors when used this kind of glass particles to batch concrete. The strength of glass concrete increased with the growth of the age, when the diameter of the glass particle less than $1.18 \mathrm{~mm}$ and the properties of the concrete are better. It can be used as concrete aggregate directly without adding alkali-silicon reaction inhibitor [4].

In aspect of the research on the content of glass aggregate, different researchers draw different conclusions from different experimental environments with different test specimens. The researches have shown that the replacement rate of waste glass is within $15 \%$, and is almost the same as the natural aggregate ${ }^{[5]}$.Some experiments also reveal that the best dosage of waste glass aggregate is from $20 \%$ to $40 \%{ }^{[6]}$.

Research on Mechanical and Durability of Glass Concrete. Domestic researchers do researches on the mechanics and durability of the glass concrete by the test ${ }^{[7]}$. Compare the partial properties of the glass concrete concluded from the test with the properties of ordinary concrete, and the conclusions are shown in table 1.

Table 1 Comparison of performance between glass concrete and ordinary concrete

\begin{tabular}{cccccc}
\hline Concrete category & strength & $\begin{array}{c}\text { properties } \\
\text { (workability) }\end{array}$ & Slump & $\begin{array}{c}\text { Corrosion } \\
\text { resistance }\end{array}$ & $\begin{array}{c}\text { Frost and thaw } \\
\text { resistance }\end{array}$ \\
\hline glass concrete & slightly $\downarrow$ & $\uparrow$ & $\uparrow$ & $\uparrow$ & $\uparrow$ \\
\hline Ordinary concrete & $\uparrow$ & $\downarrow$ & $\downarrow$ & $\downarrow$ & $\downarrow$ \\
\hline
\end{tabular}

$\uparrow$ in the table indicates that the relevant property is superior and $\downarrow$ in the table indicates that the relevant property is inferior.

Research on Alkali - Silicic Acid Reaction of the Glass Concrete. Considering that the main component of glass is silica, alkali-silicon acid reaction may occur in concrete and cause the expansion of the concrete. Some researchers study the harm of ASR expansion of green glass, brown glass, mottled glass and colorless glass with different dosages.

The research data shows that the influence of the color on ASR expansion is the most significant among the influence of dosage on the ASR expansion, the influence of the diameter of particle on ASR expansion and the influence of the color on ASR expansion. Colored glass does not cause 
ASR expansion, while the colorless waste glass causes ASR expansion obviously. The test also selects fly ash that accounts for forty percent, silica fume that accounts for twenty percent, $\mathrm{LiOH}$ that account for three percent in order to eliminate the harm caused by ASR expansion. The results show that ASR expansion inhibition rate achieved by the three substances is up to $90 \%{ }^{[8]}$.

Research on the Glass Concrete Beam and the Glass Concrete Column. The basic purpose of the research on glass concrete at home and abroad is to put the relevant achievements into practice. The beam and the column are the main components of the building. It is necessary to study the application of the glass concrete beam and the glass column when researchers do research on the application of glass concrete.

Table 2 shows the properties of the glass concrete and the properties of the ordinary concrete .The results are obtained from the analysis and comparison of the experiment data of two kinds of specimens ${ }^{[9]}$.

Table 2 Comparison between the properties of the glass concrete and the properties of the ordinary concrete

\begin{tabular}{cccc}
\hline category & $\begin{array}{c}\text { Bond force with } \\
\text { reinforcement }\end{array}$ & Bending property & Shear behavior \\
\hline $\begin{array}{c}\text { Glass fine } \\
\text { aggregate concrete } \\
\text { beam }\end{array}$ & $\begin{array}{c}\text { Higher than normal } \\
\text { concrete }\end{array}$ & $\begin{array}{c}\text { As for bearing capacity, glass fine } \\
\text { aggregate concrete beam is as the same } \\
\text { as ordinary beam. As for short-term } \\
\text { stiffness, it is higher than the ordinary } \\
\text { beam }\end{array}$ & $\begin{array}{c}\text { Shear ultimate bearing } \\
\text { capacity and ordinary } \\
\text { concrete beam similar }\end{array}$ \\
\hline $\begin{array}{c}\text { Glass coarse } \\
\text { aggregate concrete } \\
\text { beam }\end{array}$ & $\begin{array}{c}\text { Lower than normal } \\
\text { concrete }\end{array}$ & $\begin{array}{c}\text { Below the bearing capacity of beam, } \\
\text { short-term stiffness is lower than that } \\
\text { of the ordinary beam }\end{array}$ & $\begin{array}{c}\text { Shear ultimate bearing } \\
\text { capacity lower than } \\
\text { ordinary beam }\end{array}$ \\
\hline
\end{tabular}

When we do the researches on the glass concrete column, we found the failure mechanism, shape, lateral deformation, longitudinal deformation, compressive strain of concrete and steel tendon of the glass concrete column are all similar to the ordinary concrete column by the eccentric compression test of the members. We do the researches on the regular pattern of long glass concrete column's bearing capacity when the glass with the same slenderness and the different dosage or with the different slenderness and the same dosage. The conclusion is: with the same slenderness, the bearing capacity of the long glass concrete column is increasing while the dosage of the glass is increasing; with the same dosage of glass, the bearing capacity of the long glass concrete column is decreasing while the slenderness is increasing ${ }^{[10]}$.

\section{Existing Problems and Future Research Direction of the application of the Waste Glass Concrete in Civil Engineering}

Although there are many researches on the application of waste glass concrete in China, the above researches also reveal that the application of glass concrete in civil engineering project is feasible. Because the relevant researches begin late, the theoretical research is still in the initial stage and there is still a gap between the theoretical research and the actual application. Based on the analysis of the achievements and the conclusion of the above researches, it is found that there are some problems in the current research. Firstly, the implementation of garbage classification begins late in China, and there are some difficulties in the recycling of waste glass. The crushing process of waste glass is simple, but there is no precise equipment to crush the glass particles into particular size. Secondly, many of the current researches are only aimed at one aspect of glass concrete matter. Because the specimens are always made of different ingredients and the tests are done in different places, the results of the tests are inconsistent. The data and the results of the tests are not persuasive, and cannot be applied in the relevant project. Thirdly, the period of observation of properties of 
glass concrete is too short and there is no longer period of observation in relevant tests. At last, the result of existing theoretical research cannot be tested in the relevant civil engineering projects.

The above problems can be solved by accelerating the application of glass concrete in civil engineering projects. In the future research, it is very important to carry out a small-scale trial of glass concrete for long-age experimental research and sum up the advanced normative data.

\section{Acknowledgements}

The authors wish to thank Science and technology program of Liaoning Province ,China (2011222007) for sponsoring this research project.

\section{References}

[1] Zengchao. Experimental Research on Flexural Property of the Waste Glass Powder Reinforced Concrete Beams [D]. hengyang: University of South China. In Chinese.

[2] Zhanghong.2013: The Wonderful and Helpless of Chinese Concrete Industry [N].China Building Materials News,2014-1-1(005). In Chinese.

[3] Qu chao, Gao zhiyang, Liu shuhua. Research on the Application of the Waste Glass Powder in ReactivePowder Concrete [J].Concrete,2011(8):82-84.In Chinese.

[4] BARLOW D. Glass Recycling-the UK Scene [C]//Proceedings of the International Symposium Organized by the Concrete Technology Unit and Held at the University of Dundee,Scotland,UK,2001:11-14.

[5] Yang fengling, Li yushou. Research on Influence of Particle Size of the Glass Aggregate on the Property of Glass Concrete [J].Concrete,2012(8):78-80. In Chinese.

[6] Liu guangyan,Wang xiaofeng. Comparative Study on the Property and Strength of the Concrete Containing Waste Glass Coarse and Fine Aggregate [J].Concrete,2012(8):58-61. In Chinese.

[7] Zhang ni. Experimental Research on Mechanics Properties and Durability of the Glass Concrete [D].Shenyang: Shenyang Jianzhu University,2011. In Chinese.

[8] Yang hui. The Alkali-silica Reaction Test of Waste Glass Mortar [D]. Hengyang: University of South China, 2012.In Chinese.

[9] Wang zhenwei, Experimental Research on Abandoned Glass Concrete Beams [D].Shenyang: Shenyang Jianzhu University, 2012. In Chinese.

[10] Zhang qingbo. Experimental Research on the Long Concrete Column with Waste Glass [D].Shenyang: Shenyang Jianzhu University, 2012. In Chinese. 